\title{
Inhibition of microbial biofuel production in drought-stressed switchgrass hydrolysate
}

Rebecca Garlock Ong 1,2,3*, Alan Higbee ${ }^{4}$, Scott Bottoms ${ }^{5}$, Quinn Dickinson ${ }^{5}$, Dan Xie ${ }^{5}$, Scott A. Smith , Jose Serate ${ }^{5}$, Edward Pohlmann ${ }^{5}$, Arthur Daniel Jones ${ }^{6,7,8}$, Joshua J. Coon ${ }^{4,9,10}$, Trey K. Sato ${ }^{5}$, Gregg R. Sanford ${ }^{5,11}$, Dustin Eilert ${ }^{5}$, Lawrence G. Oates ${ }^{5,11}$, Jeff S. Piotrowski ${ }^{5}$, Donna M. Bates ${ }^{5}$, David Cavalier ${ }^{1}$ and Yaoping Zhang

\begin{abstract}
Background: Interannual variability in precipitation, particularly drought, can affect lignocellulosic crop biomass yields and composition, and is expected to increase biofuel yield variability. However, the effect of precipitation on downstream fermentation processes has never been directly characterized. In order to investigate the impact of interannual climate variability on biofuel production, corn stover and switchgrass were collected during 3 years with significantly different precipitation profiles, representing a major drought year (2012) and 2 years with average precipitation for the entire season (2010 and 2013). All feedstocks were AFEX (ammonia fiber expansion)-pretreated, enzymatically hydrolyzed, and the hydrolysates separately fermented using xylose-utilizing strains of Saccharomyces cerevisiae and Zymomonas mobilis. A chemical genomics approach was also used to evaluate the growth of yeast mutants in the hydrolysates.
\end{abstract}

Results: While most corn stover and switchgrass hydrolysates were readily fermented, growth of S. cerevisiae was completely inhibited in hydrolysate generated from drought-stressed switchgrass. Based on chemical genomics analysis, yeast strains deficient in genes related to protein trafficking within the cell were significantly more resistant to the drought-year switchgrass hydrolysate. Detailed biomass and hydrolysate characterization revealed that switchgrass accumulated greater concentrations of soluble sugars in response to the drought and these sugars were subsequently degraded to pyrazines and imidazoles during ammonia-based pretreatment. When added ex situ to normal switchgrass hydrolysate, imidazoles and pyrazines caused anaerobic growth inhibition of S. cerevisiae.

Conclusions: In response to the osmotic pressures experienced during drought stress, plants accumulate soluble sugars that are susceptible to degradation during chemical pretreatments. For ammonia-based pretreatment, these sugars degrade to imidazoles and pyrazines. These compounds contribute to S. cerevisiae growth inhibition in drought-year switchgrass hydrolysate. This work discovered that variation in environmental conditions during the growth of bioenergy crops could have significant detrimental effects on fermentation organisms during biofuel production. These findings are relevant to regions where climate change is predicted to cause an increased incidence of drought and to marginal lands with poor water-holding capacity, where fluctuations in soil moisture may trigger frequent drought stress response in lignocellulosic feedstocks.

Keywords: Biofuel, Corn stover, Drought, Fermentation inhibition, Lignocellulose, Saccharomyces cerevisiae, Switchgrass

\footnotetext{
*Correspondence: rgong1@mtu.edu

${ }^{3}$ Department of Chemical Engineering, Michigan Technological

University, Houghton, MI, USA

Full list of author information is available at the end of the article
} 


\section{Background}

Biofuels generated from lignocellulosic materials have enormous potential to reduce transportation-generated greenhouse gas emissions [1]. By 2030, the US could be capable of supplying as much as 1.2 billion dry tons of agricultural residues and dedicated herbaceous energy feedstocks, enough to generate 58 billion gallons of ethanol per year [2]. However, biomass production in any given year is highly dependent on weather conditions. Soil moisture levels during a growing season are affected by both past and current levels of precipitation, and are a major determinant of lignocellulosic biomass yields in non-irrigated systems [3, 4]. Low levels of precipitation and soil moisture are particularly detrimental. Plants grown under water stressed conditions have reduced photosynthesis and slower growth, which reduces biomass yields [4-6]. Drought stress can also affect plant chemical composition, often resulting in reduced levels of structural carbohydrates [7-9] and accumulation of compounds that protect against osmotic stresses, including soluble sugars and amino acids (e.g., proline) $[5,6]$. These changes in plant composition are also predicted to result in lower ethanol yields from drought-stressed feedstocks $[7,8]$, although actual fermentations have never been carried out.

A number of different potential lignocellulosic bioenergy feedstocks are being considered in the US, including agricultural residues such as corn stover (Zea mays L.), and dedicated energy crops such as switchgrass (Panicum virgatum L.). Corn stover is currently the feedstock of choice due to its current widespread availability and economic potential $[2,10]$. Switchgrass is a promising perennial bioenergy crop that can be grown on marginal lands [11] and provides superior environmental benefits compared to corn, including support for biological diversity [12], lower nitrous oxide emissions [13], and improved soil properties [14, 15]. In order to investigate how interannual variation in precipitation influences the processing characteristics and microbial fermentation of these two important biofuel feedstocks, we compared switchgrass and corn stover that were harvested following the 2012 Midwestern US drought to those harvested during two non-drought years with different precipitation patterns (2010 and 2013). In order to generate fermentable sugars, these materials were processed using ammonia fiber expansion (AFEX) pretreatment followed by enzymatic hydrolysis. The chemical composition of the feedstocks and hydrolysates were analyzed and the hydrolysates were fermented separately by Saccharomyces cerevisiae and Zymomonas mobilis. We also used a chemical genomics approach to evaluate the yeast biological response to the different hydrolysates.

\section{Results}

Drought-year switchgrass hydrolysate is inhibitory to Saccharomyces cerevisiae growth and fermentation

Corn stover (Pioneer 35H56 and P0448R) and switchgrass (Shawnee and Cave-in-Rock) were harvested from the Arlington Agricultural Research Station (ARL) in south central Wisconsin from three growing seasons (2010, 2012, and 2013) that represent, with respect to total precipitation, an average year (2010), a major drought year (2012), and a year that was wet during the first half of the growing season and dry during the second half (2013) (Fig. 1). Each feedstock was processed using AFEX pretreatment and subjected to high solid loading enzymatic hydrolysis [ 6 and 7\% glucan-loading for AFEX-treated corn stover hydrolysates (ACSH) and AFEX-treated switchgrass hydrolysates (ASGH), respectively] at previously optimized conditions [16]. Engineered xylose-utilizing ethanologens, S. cerevisiae Y128 [17] and Z. mobilis 2032 [18], were used to compare cell growth, glucose and xylose utilization, and ethanol production in the hydrolysates produced from corn stover and switchgrass harvested in different years. Z. mobilis exhibited similar growth, sugar utilization, and ethanol production for all hydrolysates, with slightly lower final cell densities but greater xylose consumption in the switchgrass hydrolysates (Fig. 2; Table 1). Saccharomyces cerevisiae showed similar growth in all corn stover hydrolysates, but reduced xylose consumption in drought-year
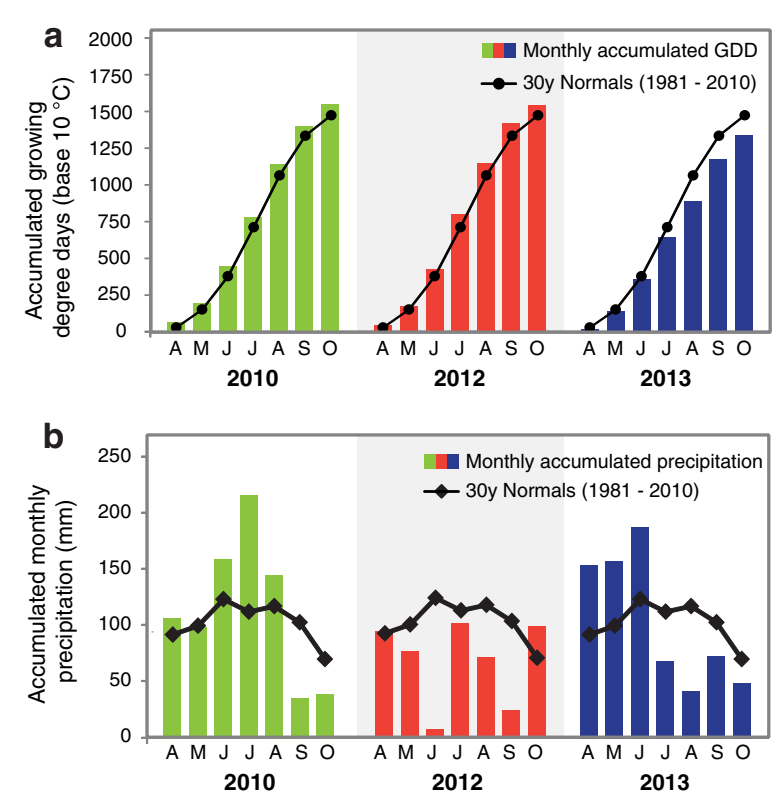

Fig. 1 Interannual weather variation. a Temperature [growing degree days (GDD)] and $\mathbf{b}$ precipitation for 2010, 2012, and 2013, and the

30-year average values at Arlington Research Station in south central

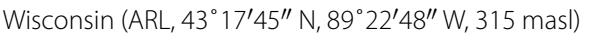



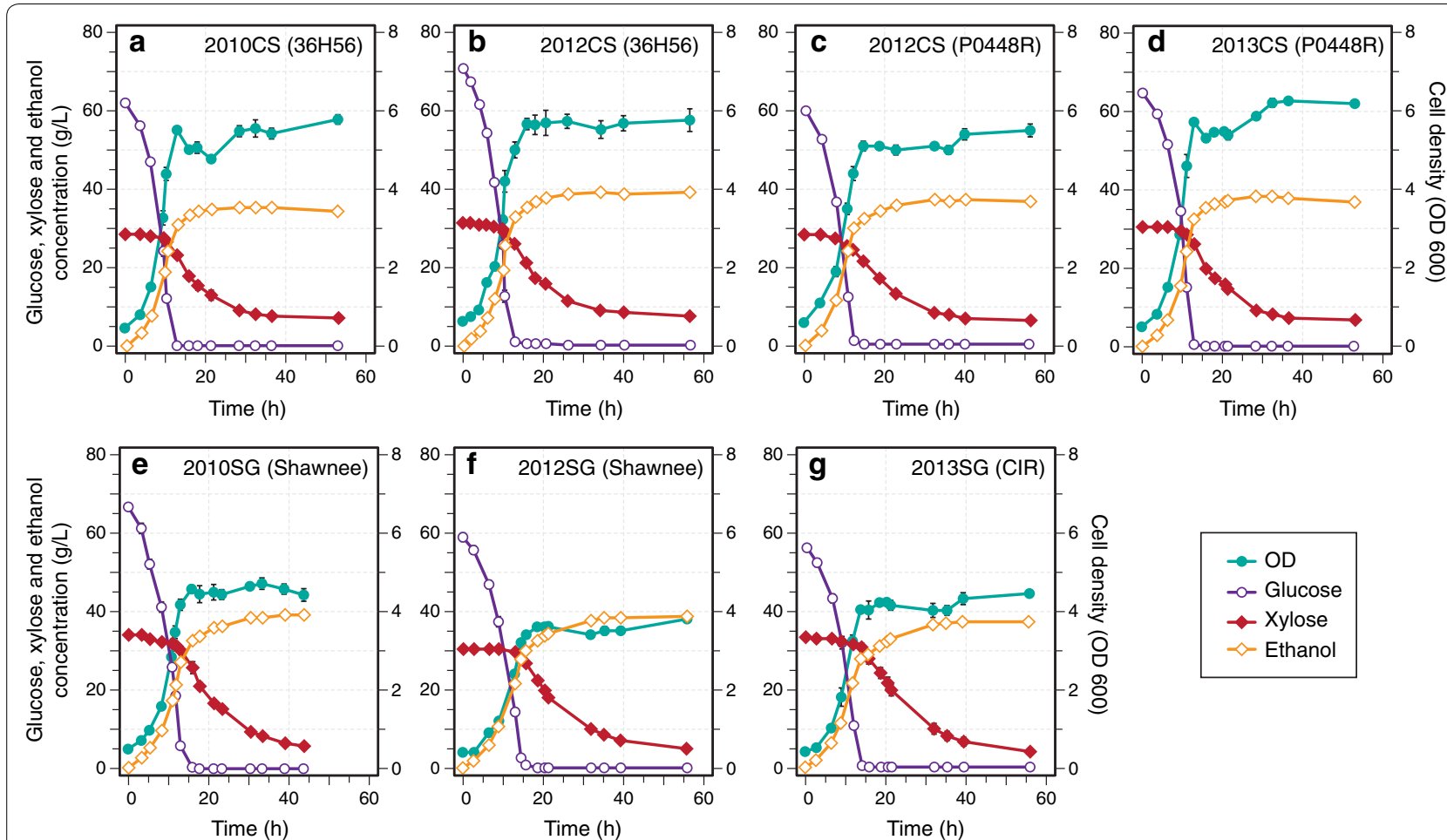

Fig. 2 Fermentation profiles for Zymomonas mobilis 2032 grown in corn stover and switchgrass hydrolysates from different harvest years. a 2010 ACSH (36H56), b 2012 ACSH (36H56), c 2012 ACSH (P0448R), d 2013 ACSH (P0448R), e 2010 ASGH (Shawnee), f 2012 ASGH (Shawnee), g 2013 ASGH [Cave-in-Rock (CIR)]. Data points represent the mean \pm SD $(n=3)$. Error bars that are smaller than the individual data points may be hidden from view

2012 ASCH (P0448R) (Fig. 3a-d; Table 1). In the 2010 and 2013 ASGH, S. cerevisiae grew and consumed xylose more slowly than in the corn stover hydrolysates harvested in the same years (Fig. 3e, g; Table 1), but completely failed to grow or ferment glucose or xylose in the drought-year 2012 ASGH (Fig. 3f). With the exception of the S. cerevisiae fermentation of 2012 ASGH, all of the fermentations achieved final ethanol concentrations of between 30 and $40 \mathrm{~g} / \mathrm{L}$ and ethanol yields of between $\sim 200$ and $300 \mathrm{~L} / \mathrm{Mg}$ untreated dry biomass $(\sim 45-70 \%$ of theoretical maximum) (Table 1).

\section{Chemical genomic analysis of hydrolysates reveals a distinct pattern for drought-year switchgrass hydrolysate} Chemical genomic analysis was used to measure the relative fitness of $~ 3500$ single-gene deletion yeast strains [19] in the hydrolysates compared to synthetic hydrolysate [16] (Additional file 1). This analysis revealed a growth sensitivity profile of the 2012 ASGH that was drastically different from all other tested hydrolysates (Fig. 4a), which displayed profiles similar to those seen for ACSH and ASGH in a previous study [16]. The two most resistant mutants to the 2012 ASGH are kex2 $\Delta$ and $v p s 5 \Delta$ (Fig. 4b): the first of which encodes a protein residing in the trans-Golgi network [20], and the latter is part of the retromer complex for recycling of proteins from the late endosome to the Golgi apparatus [21]. Of the mutants that were highly susceptible in at least one of the hydrolysates (fitness < -2.5), $65(16 \%)$ were susceptible to all five hydrolysates (Fig. 4c), with enrichment $(p<0.05)$ in genes related to amino acid biosynthesis (Additional file 2: Fig. S1). In contrast, of the 224 mutants that were highly resistant in at least one of the hydrolysates, only three were highly resistant to all five hydrolysates (fitness $>2.5$ ) (Fig. 4c): $y g r 237 c \Delta$, $y d r 474 c \Delta$, and $b c k 1 \Delta$. The contrast between the 2012 ASGH and the other four feedstocks is reflected in the fact that 57 (14\%) and 42 (19\%) of highly susceptible and resistant mutants, respectively, were only highly susceptible or resistant to the 2012 ASGH (Fig. 4c). When the highly resistant mutants were limited to only those that had a statistically significant difference compared to the other four hydrolysates $(p<0.001, n=42)$, gene ontology $(\mathrm{GO})$ terms were enriched $(p<0.05)$ for mutations related to Golgi/vesicle-mediated/vacuolar/endosomal transport and ribosome subunits (Additional file 2: Fig. S2A). The next largest intersection was for mutants that were highly resistant or susceptible to all hydrolysates 
Table 1 Summary of hydrolysis and fermentation results

\begin{tabular}{|c|c|c|c|c|c|c|c|}
\hline & \multicolumn{4}{|c|}{ Corn stover } & \multicolumn{3}{|c|}{ Switchgrass } \\
\hline & \multicolumn{2}{|l|}{$36 \mathrm{H} 56$} & \multicolumn{2}{|l|}{ P0448R } & \multicolumn{2}{|l|}{ Shawnee } & \multirow{2}{*}{$\begin{array}{l}\text { CIR } \\
2013\end{array}$} \\
\hline & 2010 & 2012 & 2012 & 2013 & 2010 & 2012 & \\
\hline \multicolumn{8}{|l|}{ Enzymatic hydrolysis } \\
\hline Glucose conversion (\%) ${ }^{\mathrm{a}}$ & $92.7 \pm 2.0$ & $92.6 \pm 1.5$ & $94.4 \pm 1.4$ & $99.0 \pm 3.0$ & $74.4 \pm 0.9$ & $69.6 \pm 2.4$ & $75.1 \pm 1.0$ \\
\hline Xylose conversion $(\%)^{\mathrm{b}}$ & $67.3 \pm 0.9$ & $69.3 \pm 1.2$ & $67.0 \pm 4.0$ & $77.1 \pm 4.2$ & $63.4 \pm 0.8$ & $61.7 \pm 5.0$ & $69.6 \pm 2.7$ \\
\hline Glucose concentration (g/L) & $64.1 \pm 1.4$ & $64.0 \pm 1.0$ & $66.5 \pm 1.0$ & $67.6 \pm 2.0$ & $59.2 \pm 0.8$ & $60.3 \pm 2.1$ & $59.4 \pm 0.8$ \\
\hline Xylose concentration (g/L) & $27.3 \pm 0.4$ & $31.7 \pm 0.5$ & $28.9 \pm 1.7$ & $30.6 \pm 1.7$ & $31.2 \pm 0.4$ & $30.7 \pm 2.5$ & $35.3 \pm 1.4$ \\
\hline \multicolumn{8}{|l|}{ Fermentation: Zymomonas mobilis } \\
\hline Final time (h) & 53.0 & 56.5 & 56.3 & 53.0 & 43.7 & 55.8 & 55.8 \\
\hline Final xylose concentration (g/L) & $7.0 \pm 1.1$ & $7.7 \pm 1.2$ & $6.6 \pm 0.4$ & $6.5 \pm 0.6$ & $5.5 \pm 0.3$ & $4.9 \pm 0.4$ & $4.1 \pm 0.6$ \\
\hline Final ethanol concentration (g/L) & $34.6 \pm 0.6$ & $39.4 \pm 0.4$ & $36.9 \pm 0.7$ & $36.7 \pm 0.8$ & $39.0 \pm 1.2$ & $38.9 \pm 0.8$ & $37.3 \pm 0.5$ \\
\hline Metabolic yield $(\%)^{c}$ & $80.4 \pm 2.8$ & $87.9 \pm 2.1$ & $81.4 \pm 2.9$ & $78.5 \pm 3.6$ & $90.2 \pm 3.1$ & $88.7 \pm 4.3$ & $80.6 \pm 2.3$ \\
\hline Process yield $(\%)^{d}$ & $74.2 \pm 2.4$ & $80.8 \pm 1.5$ & $75.7 \pm 2.8$ & $73.3 \pm 3.4$ & $84.6 \pm 3.1$ & $83.9 \pm 4.1$ & $77.1 \pm 2.1$ \\
\hline Ethanol yield (L/Mg untreated dry biomass) & $230 \pm 4$ & $262 \pm 2$ & $255 \pm 5$ & $288 \pm 6$ & $246 \pm 7$ & $214 \pm 5$ & $245 \pm 3$ \\
\hline Max theoretical ethanol yield (L/Mg untreated dry biomass) ${ }^{e}$ & $371 \pm 2$ & $389 \pm 2$ & $401 \pm 2$ & $432 \pm 1$ & $415 \pm 1$ & $382 \pm 3$ & $437 \pm 2$ \\
\hline Ethanol yield (\% of maximum) & $61.8 \pm 1.8$ & $67.3 \pm 1.1$ & $63.6 \pm 1.9$ & $66.7 \pm 2.1$ & $59.4 \pm 3.0$ & $56.0 \pm 2.3$ & $56.2 \pm 1.4$ \\
\hline \multicolumn{8}{|l|}{ Fermentation: Saccharomyces cerevisiae } \\
\hline Final time $(h)$ & 56.5 & 50.8 & 60.8 & 60.8 & 55.5 & 57.3 & 57.3 \\
\hline Final xylose concentration (g/L) & $4.7 \pm 1.0$ & $7.3 \pm 4.5$ & $19.9 \pm 1.7$ & $4.0 \pm 0.6$ & $14.2 \pm 2.1$ & $40.1 \pm 3.7$ & $25.4 \pm 2.0$ \\
\hline Final ethanol concentration (g/L) & $36.6 \pm 0.9$ & $36.3 \pm 2.9$ & $34.0 \pm 1.0$ & $39.8 \pm 0.3$ & $35.3 \pm 0.5$ & $0.2 \pm 0.0$ & $30.6 \pm 0.5$ \\
\hline Metabolic yield $(\%)^{c}$ & $82.8 \pm 3.1$ & $80.5 \pm 9.5$ & $88.4 \pm 4.5$ & $82.9 \pm 2.9$ & $90.7 \pm 3.3$ & $-5.4 \pm 75.2$ & $86.5 \pm 4.0$ \\
\hline Process yield $(\%)^{d}$ & $78.6 \pm 2.9$ & $74.3 \pm 8.0$ & $69.9 \pm 3.6$ & $79.4 \pm 2.8$ & $76.5 \pm 1.6$ & $0.4 \pm 11.6$ & $63.3 \pm 2.3$ \\
\hline Ethanol yield (L/Mg untreated dry biomass) & $243 \pm 6$ & $241 \pm 19$ & $236 \pm 7$ & $312 \pm 2$ & $223 \pm 3$ & $1 \pm 0$ & $202 \pm 3$ \\
\hline Max theoretical ethanol yield (L/Mg untreated dry biomass) ${ }^{e}$ & $371 \pm 2$ & $389 \pm 2$ & $401 \pm 2$ & $432 \pm 1$ & $415 \pm 1$ & $382 \pm 3$ & $437 \pm 2$ \\
\hline Ethanol yield (\% of maximum) & $65.5 \pm 2.4$ & $61.9 \pm 8.0$ & $58.7 \pm 2.9$ & $72.2 \pm 0.7$ & $53.7 \pm 1.4$ & $0.3 \pm 11.1$ & $46.2 \pm 1.6$ \\
\hline
\end{tabular}

Values are reported as the mean \pm SD $(n=3)$. Propagation of error was conducted to obtain SD values for all calculated values

a The glucose conversion was calculated based on the total glucan, soluble glucose, and glucose contributed by sucrose in the untreated biomass using a previously reported equation [51]

b The xylose conversion was calculated as $\mathrm{Xyl} /\left[\mathrm{BL}{ }^{*} \mathrm{X} \ln (150 / 132)\right]$, where $\mathrm{Xyl}=$ hydrolysate $x y l$ lose concentration $(\mathrm{g} / \mathrm{L}), \mathrm{BL}=\mathrm{biomass}$ loading $(\mathrm{g} / \mathrm{L}), \mathrm{XIn}=\mathrm{untreated}$ biomass xylan content ( $\mathrm{g} / \mathrm{g}$ biomass), and 150/132 are the molecular weights of xylose/xylan

c The metabolic yield is the ratio of sugars (glucose and xylose) consumed during fermentation to ethanol produced assuming $0.51 \mathrm{~g}$ ethanol/g sugars as the theoretical maximum

$\mathrm{d}$ The process yield is the ratio of sugars initially present in the hydrolysate (glucose and xylose) to ethanol produced assuming $0.51 \mathrm{~g}$ ethanol/g sugars as the theoretical maximum

e The maximum theoretical ethanol yield is calculated based on the complete conversion of all glucose (as glucan, free glucose, or part of sucrose) and xylose (as xylan) in the untreated biomass to ethanol assuming $0.51 \mathrm{~g}$ ethanol $/ \mathrm{g}$ sugars

except the 2012 ASGH. When limited to highly susceptible mutants that had a statistically significant difference for the four hydrolysates compared to the 2012 ASGH $(n=56, p<0.001), \mathrm{GO}$ terms were enriched $(p<0.05)$ related to the mitochondrial-nucleus signaling pathway, and Golgi/vacuolar transport (Additional file 2: Fig. S2B). No significant terms were found for the mutants that were only highly susceptible to the 2012 ASGH or only highly resistant to the other four feedstocks. Gene set enrichment analysis was used to evaluate whether any yeast metabolic pathways (using the KEGG pathway collection) were enriched for the mutants that were significantly different between the 2012 ASGH and the four other feedstocks $(p<0.001)$. This analysis revealed three KEGG pathways (FDR $<0.25$ ) that were dominated by mutants that were resistant to the 2012 ASGH and susceptible to the hydrolysates of the other four feedstocks: SNARE interactions in vesicular transport, endocytosis, and the ribosome. For the SNARE pathway, the gene deletions that conferred greater resistance in 2012 ASGH compared to the other hydrolysates $(p<0.001)$ were GOS1, VAM7, and SEC22, which are all involved in vesicle traffic between the ER, Golgi, endosome, and vacuole. 

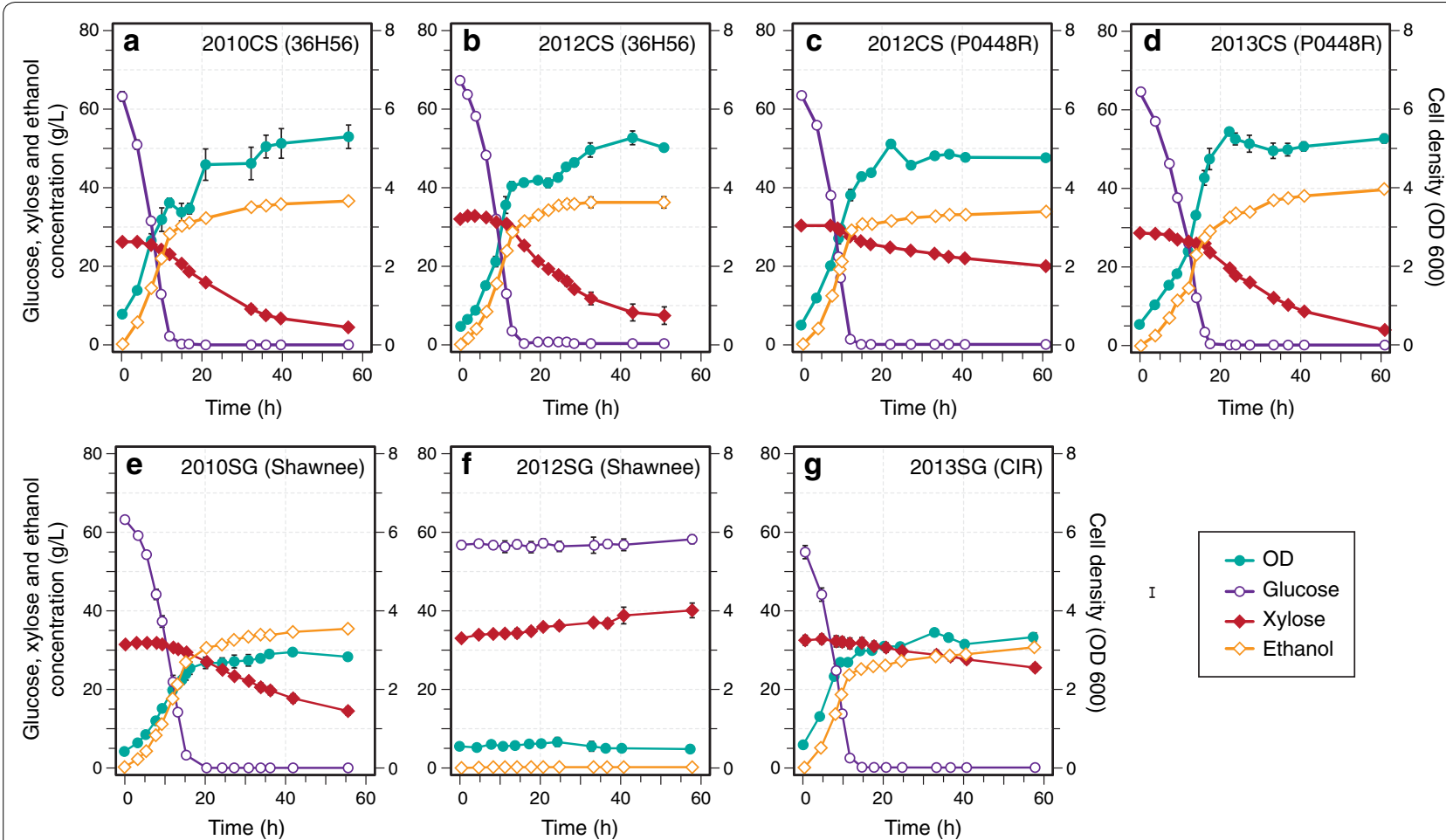

Fig. 3 Fermentation profiles for Saccharomyces cerevisiae Y128 grown in AFEX-treated biomass hydrolysates. a 2010 ACSH (36H56), b 2012 ACSH (36H56), c 2012 ACSH (P0448R), d 2013 ACSH (P0448R), e 2010 ASGH (Shawnee), f 2012 ASGH (Shawnee), g 2013 ASGH [Cave-in-Rock (CIR)]. Data points represent the mean $\pm S D(n=3)$. Error bars that are smaller than the individual data points may be hidden from view

\section{Imidazoles and pyrazines are present in high}

\section{concentrations in drought-year switchgrass hydrolysate}

To identify the cause of severe growth inhibition in the 2012 ASGH, we compared the compositions of the untreated biomass (Fig. 5; Additional file 2: Table S1), hydrolysates (Additional file 2: Tables S2-S4), and extracts of the pretreated biomass. As is typical for drought-stressed grasses [7, 22], untreated 2012 switchgrass contained higher total extractives (water- and ethanol-extractable compounds) and soluble sugars (Fig. 5a) and lower structural carbohydrates and lignin compared to the 2010 and 2013 switchgrass (Fig. 5b). A number of amino acids, metals, and furanic and phenolic compounds were also directly quantified from the hydrolysates (Additional file 2: Tables S2-S4). With the exception of the 2010 and 2013 ASGH, which overlapped, all the hydrolysates were readily distinguishable by principal component analysis (PCA) of their hydrolysate compositions (Fig. 6). The greatest amount of variation (31\%) was attributed to the difference between plant species (corn stover vs. switchgrass) (Fig. 6a), followed by the difference between 2010/2013 and 2012 hydrolysates ( $22 \%$ of variance) (Fig. $6 \mathrm{~b}$ ). Of all the compounds in the hydrolysate, the amino acid content had the largest influence on segregation of the 2012 feedstocks (Fig. 6c).
When looking at the compounds individually, compared to the other hydrolysates, the 2012 ASGH had statistically higher $(p<0.05)$ levels of benzamide $(10 \mu \mathrm{M})$, vanillyl alcohol $(0.8 \mu \mathrm{M})$, sulfur $(5.4 \mathrm{mM})$, chloride $(96.6 \mathrm{mM}-$ largely from $\mathrm{HCl}$ used to neutralize the hydrolysate), magnesium (24.4 mM), total nitrogen (307.3 mM), proline $(1.46 \mathrm{mM})$, and tryptophan $(42.5 \mu \mathrm{M})$.

In order to determine whether any additional compounds were present that might be responsible for the inhibition, the hydrolysates were extracted with ethyl acetate and analyzed. These extracts revealed the presence of higher levels of pyrazines in the drought-year (2012) ASGH compared to the other switchgrass hydrolysates (Fig. 7a). Seven substituted imidazoles and pyrazines were further quantified from acetone extracts of the untreated and pretreated biomass. These compounds were found at higher levels in pretreated biomass samples and were either present at very low concentrations (imidazoles) or absent in the untreated biomass, indicating that they were produced during the AFEX pretreatment process (Fig. 7b). Pretreated switchgrass contained more pyrazines than pretreated corn stover, and the drought-year (2012) switchgrass exhibited the highest concentration of pyrazines. Combined imidazole and pyrazine levels after pretreatment correlated with the 


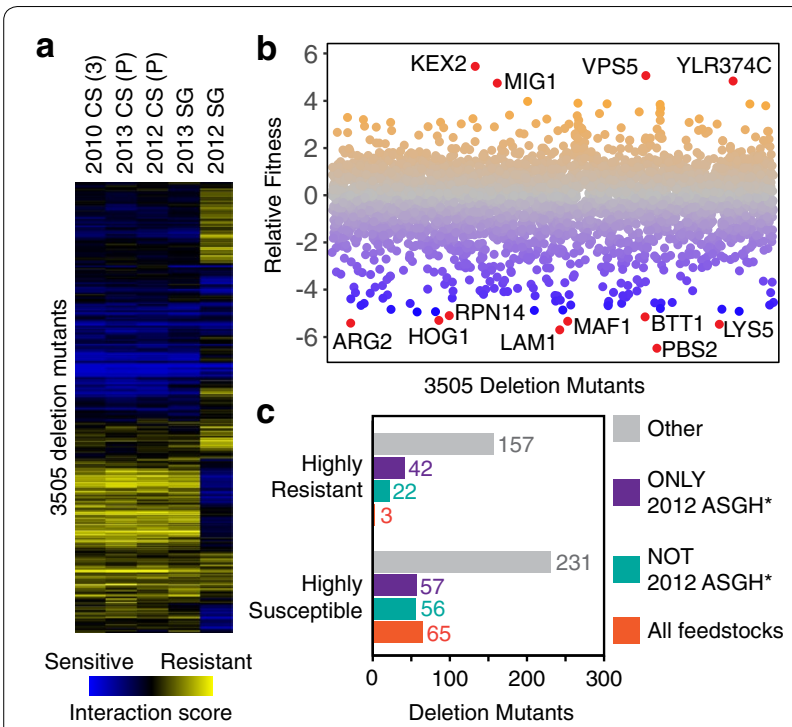

Fig. 4 Chemical genomic analysis of hydrolysate variation. a Fitness heat map for yeast mutants in corn stover (CS) and switchgrass (SG) hydrolysates. The genome-wide yeast deletion mutant collection was grown in fifteen different hydrolysate batches ( $n=3$ per feedstock) and a synthetic hydrolysate (SynH2.1) control $(n=3)$. The abundance of each mutant was assessed by sequencing the strain-specific barcodes and a fitness score was determined relative to the synthetic hydrolysate control. Mutants sensitive to the hydrolysate conditions are shown in blue and resistant are shown in yellow, compared to the abundance in the SynH2.1 control. The (3) represents the $36 \mathrm{H} 56$ variety and the $(P)$ represents the P0448R variety of corn stover. $\mathbf{b}$ Fitness plot of yeast mutants grown in 2012 ASGH. The most resistant (fitness $>4$ ) and susceptible mutants (fitness $<-5$ ) are labeled and shown in red. c Intersection of yeast mutants that are highly susceptible or resistant to all hydrolysates, only the 2012 ASGH, or all hydrolysates except the 2012 ASGH. *The fitness of these mutants was statistically different $(p<0.001)$ in the 2012 ASGH versus the other four hydrolysates [2013 ASGH, 2010 CS (36H56), 2012 CS (P0448R), 2013 CS (P0448R)]

soluble sugar content of the untreated biomass (Fig. 7c). The concentrations of imidazoles and pyrazines in the hydrolysates were estimated based on their concentrations in the pretreated biomass (Table 2). The total estimated concentration of all imidazoles and pyrazines in the 2012 ASGH was almost twice that of the next highest sample, 2013 ACSH (P0448R) (Table 2), and the concentrations of 2-methylimidazole, 4(5)-methylimidazole, and 2-methylpyrazine were higher than the majority of the other aromatic compounds that were characterized in the 2012 ASGH (Table 2; Additional file 2: Table S2). Acetamide and four of the top five most abundant low molecular weight phenolics (coumaroyl amide, feruloyl amide, coumaric acid, and vanillin) were at higher levels in the readily fermentable 2012 ACSH (36H56) compared to the inhibitory 2012 ASGH (Table 2).

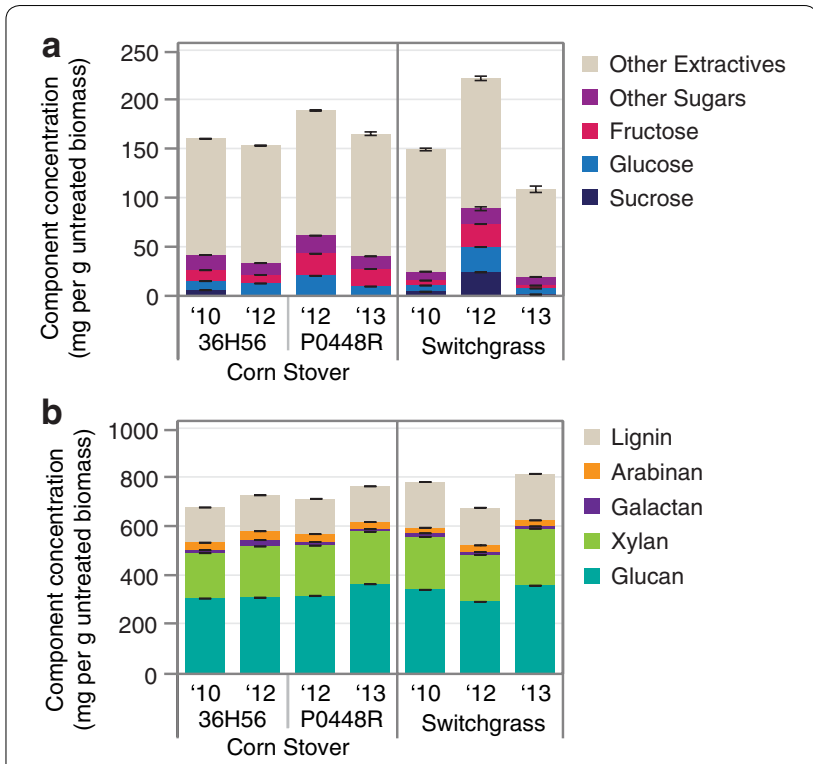

Fig. 5 Untreated biomass composition. a Water and ethanol soluble extractives. b Structural carbohydrates and lignin. Values are reported as the mean $\pm \mathrm{SD}(n=3)$

\section{Imidazoles and pyrazines contribute to the inhibition of $S$. cerevisiae}

In order to determine whether elevated imidazoles and pyrazines contribute to the anaerobic growth inhibition of S. cerevisiae Y128 in the 2012 ASGH, we added these compounds into the non-inhibitory 2010 ASGH at the levels estimated in 2012 ASGH and up to 50 times the concentration. Prior to supplementation with additional imidazoles and pyrazines, the 2010 ASGH supported yeast growth and fermentation (Figs. 3e, 8). While there was still growth at the concentration of imidazoles and pyrazines in the 2012 ASGH $(1 \times)$, growth began to be delayed at 25 times the concentration $(25 \times)$, with complete inhibition at 50 times the concentration $(50 \times)$ within the fermentation time frame. These results correspond to the $\mathrm{IC}_{50}$ values, where at comparable concentrations the individual imidazoles and pyrazines reduced growth of $S$. cerevisiae by $50 \%$, with the imidazoles more strongly inhibitory (Table 3).

\section{Discussion}

During the severe Midwestern drought in 2012, soluble sugars accumulated to significantly higher levels in switchgrass compared to during two non-drought years in 2010 and 2013. During ammonia-based pretreatment (AFEX), these soluble sugars underwent Maillard reactions with ammonia to form aromatic nitrogenous compounds, imidazoles and pyrazines [23, 24]. Both classes of compounds can be highly toxic [26] and many 

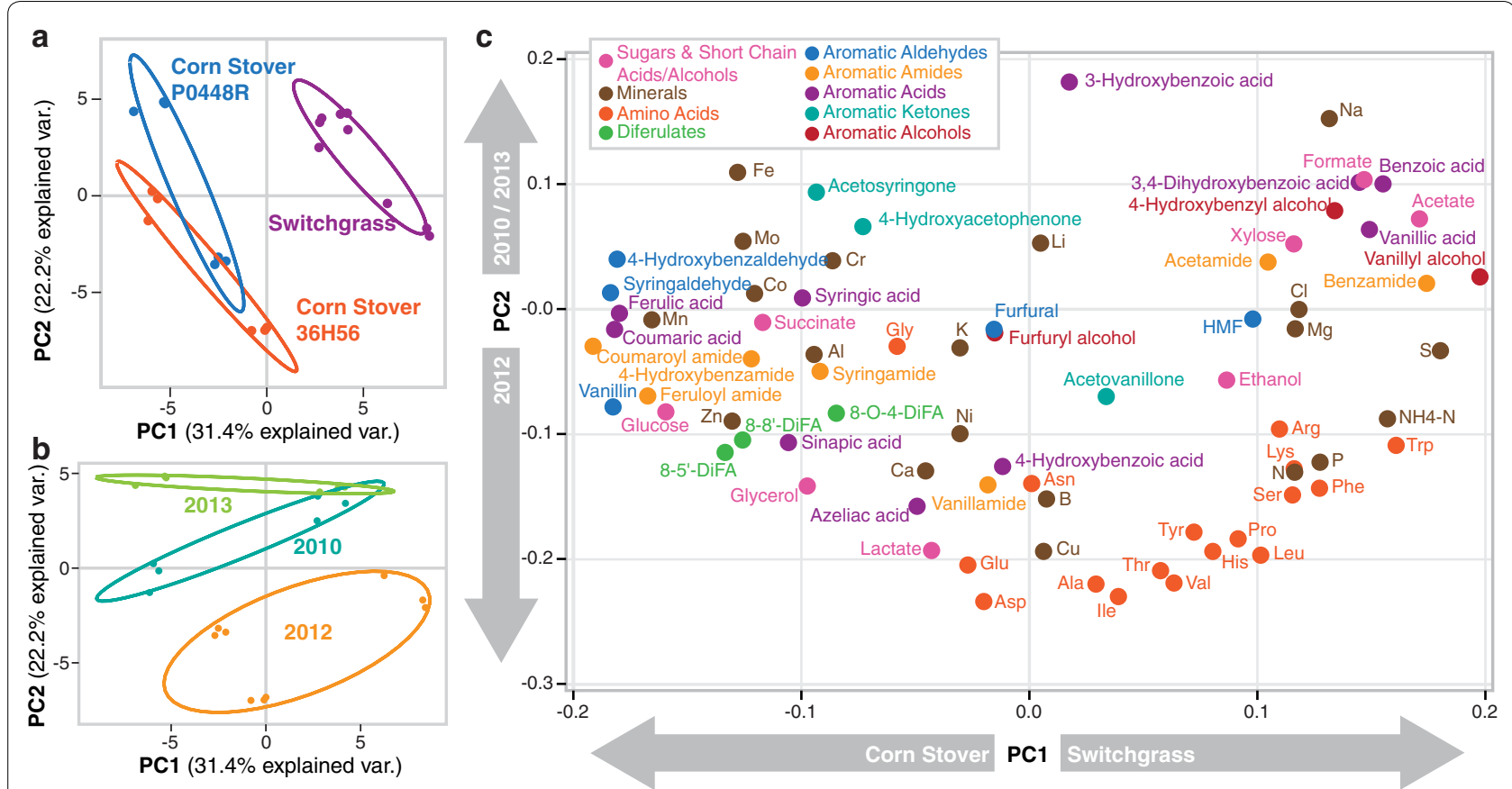

Fig. 6 Principal component analysis (PCA) of hydrolysate composition data-relationship between principal components 1 and 2. a Hydrolysate batches grouped by plant variety. b Hydrolysate batches grouped by year. c Correlation score graph showing relative effect of each hydrolysate component

complex azoles are potent antifungal agents [25]. Our data suggest that these compounds contributed to inhibition of fermentative yeast growth in drought-stressed switchgrass (Fig. 9); however, they are most likely not the sole cause. A previous study predicted reductions of $10-15 \%$ in the theoretical ethanol yield from lignocellulosic biomass harvested during a drought year compared to a non-drought year, largely due to the negative effects of drought on the biomass structural sugar content [7]. In our study, while in some cases there was a reduction in the actual ethanol yield for drought-year feedstocks ( $-7 \%$ for CS-P0448R and SG), this was not always the case $(+12 \%$ for CS-36H56 for 2012 vs. 2010) (Table 1$)$. The actual ethanol yield also varied significantly between feedstocks (from 46 to $72 \%$ of the theoretical maximum) in a manner that was not obvious based on the untreated biomass composition. Additionally, the complete inhibition of the yeast growth in the 2012 ASGH, while related to the biomass composition, was not predictable based on the current state of knowledge. In order to design feedstocks and processes that are able to either accommodate or reduce feedstock variability, more studies are needed that focus on understanding how external factors influence biomass quality and subsequently affect fermentation performance.

Although the drought had some negative effects on hydrolysate composition, it also had a number of positive effects, particularly related to hydrolysate amino acid concentrations. With the exception of glycine and asparagine, the drought-year hydrolysate for each respective feedstock had the highest concentration of each amino acid, and of all hydrolysates the 2012 ASGH had the highest concentration for both proline and tryptophan (Additional file 2: Table S4). Plants commonly respond to drought or other abiotic stresses by accumulating amino acids $[5,26]$. In particular, proline is produced by drought-stressed plants to help regulate osmotic pressure [5] and both proline and tryptophan have been reported at higher levels in drought-stressed grasses compared to their unstressed counterparts $[6,22]$. For pretreatments, such as AFEX, that do not denature, degrade, or remove proteins and amino acids, the retention of amino acids in the hydrolysate provides a beneficial source of nutrients for the microorganism [27]. The importance of these amino acids to microbial fitness in the hydrolysates is apparent from the large number of amino acid biosynthetic mutants that were highly susceptible in all of the five hydrolysates investigated (Additional file 2: Fig. S1).

In our study, the soluble sugars that were present in the lignocellulosic biomass were degraded to inhibitory imidazoles and pyrazines following ammonia-based pretreatment. However, for other pretreatment methods, the soluble sugars that accumulate in drought-stressed biomass can also be degraded to other inhibitory compounds, 

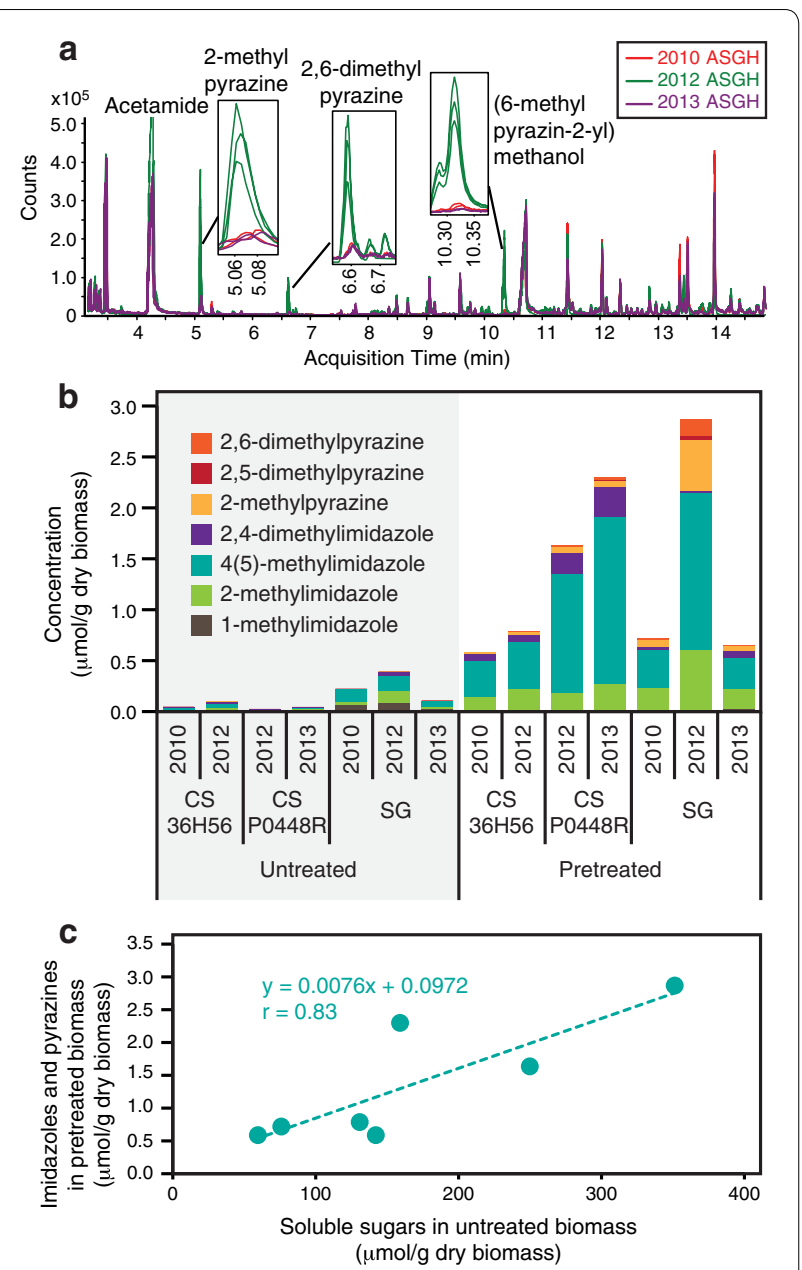

Fig. 7 Imidazole and pyrazine detection and quantification in AFEXtreated biomass and hydrolysates. a Overlaid mass spectrometric chromatogram of ethyl acetate extracts of AFEX-treated switchgrass hydrolysates. Each line represents a replicate batch of hydrolysate (2012: $n=3 ; 2010$ and 2013: $n=2$ ). b Imidazole and pyrazine content of untreated and AFEX-treated corn stover (CS) and switchgrass (SG). c Correlation between imidazole and pyrazine content of AFEX-treated biomass and untreated biomass soluble sugars (sucrose, glucose fructose, xylose, arabinose, and galactose)

in the case of dilute acid to furfural, 5-hydroxymethylfurfural, levulinic acid, and formic acid [28]. These compounds can cause severe negative effects on microbial fermentation for both yeast and bacteria [29, 30]. Thus, degradation of soluble sugars that are present in droughtstressed crops poses a potential problem for lignocellulosic biofuel production regardless of the pretreatment used. However, it may be possible to overcome the inhibition by adjusting pretreatment conditions to limit formation of harmful compounds, removing soluble sugars prior to processing, or utilizing more resistant microbial strains. For example, it may be preferable to use the bacterium $Z$. mobilis 2032, which was less susceptible to growth inhibition in the 2012 ASGH compared to the yeast S. cerevisiae Y128 (Figs. 2, 3).

Analysis of the chemical genomics data indicates that the 2012 ASGH had an impact on the protein trafficking system within the yeast cell, particularly in relationship to the late endosome and retromer, which is responsible for recycling of certain proteins from the late endosome to the Golgi apparatus. In yeast, the retromer consists of two subcomplexes: a trimer consisting of Vps26p, Vps29p, and Vps35p and a dimer consisting of Vps5p and Vps17p [21]. A number of mutants related to these systems, in particular the three retromer subunits for which we had mutants (vps35 $\Delta$, vps5 5 , and $v p s 17 \Delta$ ), were highly susceptible to reduced growth in the four other hydrolysates that were investigated (2010, 2012-P0448R and 2013 ACSH, and 2013 ASGH) but had greater fitness in the 2012 ASGH. If the mechanism of inhibition in the 2012 ASGH is related to the endosomal system and vesicular transport between the organelles, this could explain the difference observed with the bacterial ethanologen Z. mobilis, which has neither organelles nor the process of endocytosis, and was able to grow with no difficulty in the 2012 ASGH.

Plants experience drought stress in response to low levels of soil moisture. Although there are benefits to growing dedicated bioenergy crops like switchgrass on marginal lands to avoid competition with food crop production [31], some marginal lands are classified as such because their soil has poor water-holding capacity [32]. Plants grown on these soils may experience greater drought stress and produce more osmoprotective soluble sugars than plants grown on more fertile soils. Climate change may further aggravate these issues as extreme precipitation events are predicted to increase [33]. Intense rainfall followed by longer dry spells limits the replenishment of soil moisture [33], and in certain regions this may negatively influence biomass yields and processing characteristics. Moisture stress will be an issue for bioenergy production systems that needs to be addressed, not just because of the impact on crop yields, but also because of the potential negative impact on biomass quality.

\section{Conclusions}

Drought induces the accumulation of high concentrations of soluble sugars in lignocellulosic bioenergy crops. During ammonia-based pretreatment, these sugars are degraded to imidazoles and pyrazines that during fermentation contribute to growth inhibition of the yeast $S$. cerevisiae, but do not negatively affect the bacterium $Z$. mobilis. This is the first study that links compounds generated during the processing of environmentally stressed lignocellulosic biomass to deleterious impacts on the microbes during biofuel production. Our findings have 
Table 2 Concentrations $(\mu \mathrm{M})$ of imidazoles and pyrazines (estimated) and aromatic degradation products in pretreated biomass hydrolysates

\begin{tabular}{|c|c|c|c|c|c|c|c|}
\hline & Corn s & H56 & Corn sto & $448 R$ & Switcl & & \\
\hline & 2010 & 2012 & 2012 & 2013 & 2010 & 2012 & 2013 \\
\hline 1-Methylimidazole & 2 & 0 & ND & 0 & 1 & 1 & 5 \\
\hline 2-Methylimidazole & 26 & 42 & 33 & 44 & 45 & 137 & 37 \\
\hline 4(5)-Methylimidazole & 67 & 86 & 214 & 264 & 76 & 356 & 60 \\
\hline 2,4-Dimethylimidazole & 13 & 14 & 36 & 49 & 5 & 6 & 12 \\
\hline 2-Methylpyrazine & 4 & 6 & 11 & 10 & 14 & 114 & 10 \\
\hline 2,5-Dimethylpyrazine & 0 & 0 & 1 & 1 & 1 & 9 & 1 \\
\hline 2,6-Dimethylpyrazine & 1 & 1 & 4 & 4 & 3 & 38 & 2 \\
\hline Sum of imidazoles and pyrazines & 112 & 150 & 299 & 371 & 144 & 661 & 126 \\
\hline Acetamide & 7755 & 7114 & 8283 & 8309 & 8888 & 11,372 & 8981 \\
\hline Coumaroyl amide & 5034 & 3152 & 3763 & 4502 & 1622 & 1751 & 1908 \\
\hline Feruloyl amide & 2044 & 1529 & 2181 & 2186 & 593 & 1179 & 753 \\
\hline Coumaric acid & 1328 & 489 & 774 & 937 & 225 & 268 & 257 \\
\hline Benzoic acid & 132 & 168 & 121 & 124 & 304 & 225 & 300 \\
\hline Vanillin & 181 & 141 & 156 & 146 & 71 & 69 & 86 \\
\hline
\end{tabular}

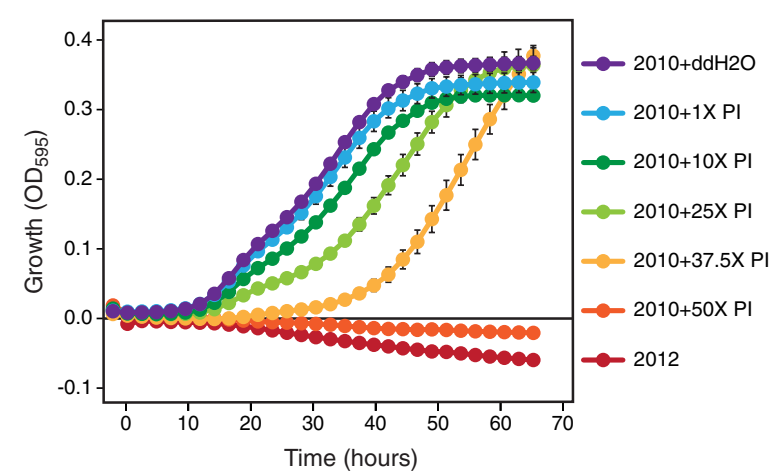

Fig. 8 Imidazoles and pyrazines found in drought-year AFEX-treated switchgrass hydrolysate (ASGH) can impair anaerobic yeast growth. Anaerobic yeast growth in add-back experiment, with various concentrations of pyrazines and imidazoles (P/l) in 2010 ASGH relative to estimated levels in 2012 ASGH (mean, $n=3$ ). Average cell densities with standard error of the mean are reported from triplicate samples, with every twelfth time point plotted (roughly one time point every $2 \mathrm{~h}$

profound implications for the development of sustainable lignocellulosic biofuel production systems that are able to tolerate fluctuations in precipitation and water availability.

\section{Methods}

The methods for AFEX pretreatment; high solids enzymatic hydrolysis; chemical analysis of hydrolysate composition; and strains, media, growth and fermentation conditions are the same as previously reported [16].

\section{Feedstock production, harvest, and processing}

Switchgrass and corn stover were cultivated at the Arlington Agricultural Research Station (ARL, 43 $17^{\prime} 45^{\prime \prime}$ $\mathrm{N}, 89^{\circ} 22^{\prime} 48^{\prime \prime} \mathrm{W}, 315$ masl) in Arlington, Wisconsin. Corn stover was sourced from Arlington field 744 (ARL-744) in 2010, ARL-570 in 2012, and ARL-742 in 2013. Switchgrass was sourced from ARL-346 in both 2010 and 2012, and ARL-115 in 2013. The main soil at ARL is Plano siltloam (fine-silty, mixed, superactive, mesic Typic Argiudoll); a deep ( $>1 \mathrm{~m})$, well-drained mollisol developed over glacial till and formed under tallgrass prairie [13]. Mean annual temperature and precipitation are $6.9{ }^{\circ} \mathrm{C}$ and $869 \mathrm{~mm}$, respectively [34, 35].

Pioneer 36H56 and P0448R corn stover (both triple stacked with Roundup Ready and corn borer and rootworm resistance) were planted on May 3 (2010) and May 11 (2012) for 36H56, and May 11 (2012) and May 15 (2013) for P0448R. Fertilizer (0-0-50 potassium sulfate) was applied in 2010 after 4 years of alfalfa. In 2012, both corn varieties received $92 \mathrm{~kg} \mathrm{~N} / \mathrm{ha}$ as anhydrous in April, whereas 2013 corn received $83 \mathrm{~kg} \mathrm{~N} / \mathrm{ha}$ as urea in May. Weed control was attended on ARL-744 with a pre-emerge (Metolachlor: $1848 \mathrm{~mL} \mathrm{AI/ha)} \mathrm{and} \mathrm{post-}$ emerge herbicide (Dicamba; Diflufenzopyr: $267 \mathrm{~mL} \mathrm{AI} /$ ha) applied on May 10 and June 10, 2010, respectively. For field ARL-570, a mixed pre-emerge herbicide (2,4-D LV4 Ester; Glyphosate; Mesotrione; S-Metolachlor: $1264 \mathrm{~mL} \mathrm{AI} / \mathrm{ha}$ ) was applied on April 16, 2012 prior to planting and a mixed post-emerge herbicide (Glyphosate; Tembotrione; Ammonium Sulfate; Methylated Seed Oil: $852 \mathrm{~mL} \mathrm{AI} / \mathrm{ha}$ ) on June 8, 2012. The herbicide treatment 
Table 3 IC $_{50}$ values of selected nitrogenous compounds for Saccharomyces cerevisiae Y128

\begin{tabular}{ll}
\hline Compound & $\mathbf{I C}_{\mathbf{5 0}} \mathbf{( \mathbf { m M } )}$ \\
\hline 2-Methylimidazole & $50.9 \pm 0.7$ \\
4(5)-Methylimidazole & $25.2 \pm 1.0$ \\
2,4-Dimethylimidazole & $33.1 \pm 10.4$ \\
2-Methylpyrazine & $>100^{\mathrm{a}}$ \\
2,3-Dimethylpyrazine & $83.9 \pm 7.5$ \\
2,5-Dimethylpyrazine & $80.9 \pm 4.8$ \\
2,6-Dimethylpyrazine & $82.6 \pm 3.8$ \\
2,3,5-Trimethylpyrazine & $66.8 \pm 3.5$ \\
(5-Methylpyrazin-2-yl)methanol & $>80^{\mathrm{a}}$
\end{tabular}

$\mathrm{IC}_{50}$ values are reported as the mean $\pm \operatorname{SEM}(n=3)$

a All replicates had no growth inhibition for the range of concentrations tested

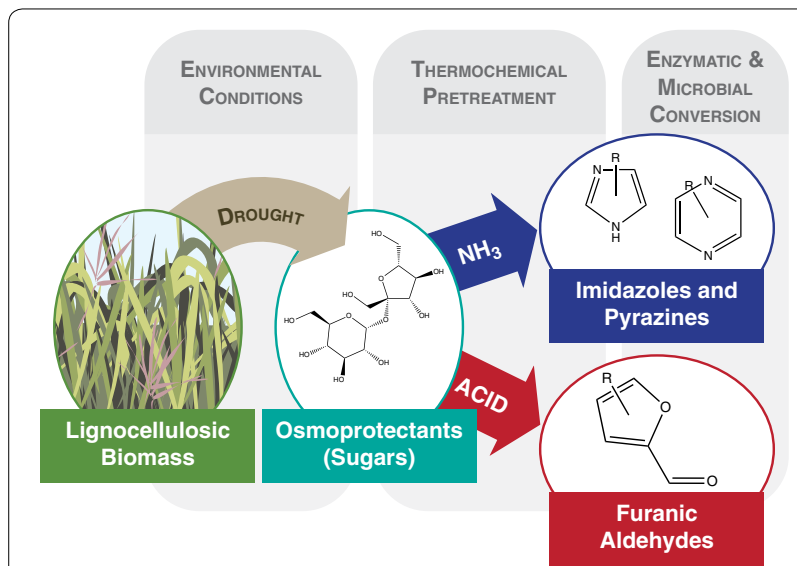

Fig. 9 Interaction between plant response to environmental conditions and pretreatment chemistry. In lignocellulosic biomass, drought stress causes an increase in osmoprotectants, including soluble sugars that are degraded to microbial inhibitors during thermochemical pretreatments

on ARL-742 used Mesotrione: $175 \mathrm{~mL} \mathrm{AI/ha} \mathrm{+} \mathrm{S-Metol-}$ achlor: $1685 \mathrm{~mL} \mathrm{AI/ha.} \mathrm{Corn} \mathrm{stover} \mathrm{was} \mathrm{collected} \mathrm{shortly}$ after grain harvest in early November of all years using a combine that had been modified to separate the corn grain and then chop and bail the corn stover.

Switchgrass (Shawnee variety; 2010 and 2012) was planted on May 29, 2004 using a Brillion Sure Stand seeder (Landoll Corporation, Marysville, KS) at a rate of $16.8 \mathrm{~kg} / \mathrm{ha}$. For initial weed control, Quinclorac herbicide $(1445 \mathrm{~mL} \mathrm{Al} / \mathrm{ha})$ was applied 1 day after planting. A tank mix of Imazethapyr $(259 \mathrm{ml} \mathrm{Al} / \mathrm{ha})$ and Dicamba (1445 mL Al/ha) was applied on May 19, 2006 for additional weed control. Each year in April, granular urea (46-0-0) was top-dressed at a rate of $90 \mathrm{~kg} / \mathrm{ha}$. In midOctober 2010, switchgrass was cut and conditioned with a 4.5-m-wide haybine (John Deere 4990). Switchgrass sourced in 2013 (Cave-in-Rock) was planted in late June
2008 using a drop spreader (Truax Company, Inc.) with two culti-pack rollers at a rate of $14 \mathrm{~kg} / \mathrm{ha}$. Initial weed control was accomplished with Glyphosate $(700 \mathrm{~mL} \mathrm{AI} /$ ha) on June 17, 2008 and again as a pre-emerge treatment on April 23, 2009 and May 3, 2010. Post-emerge weed control was applied as 2,4-D (773 mL AI/ha) on June 26 , 2009 and May 10, 2010. Starting in 2010, 56 kg/ha (34-0-0 ammonium nitrate) was applied annually, and in $2013 \mathrm{~N}$ was applied on May 30. In mid- to late-September (2010 and 2012) and mid-October (2013), biomass was cut and windrowed, and then chopped with a self-propelled forage harvester into a dump wagon equipped with load cells.

Following harvest, each corn stover and switchgrass material was dried in a $60{ }^{\circ} \mathrm{C}$ oven until the dry weight was stable $(\sim 48 \mathrm{~h})$, then milled using a 18-7-301 SchutteBuffalo hammer mill (SchutteBuffalo, Buffalo, NY) equipped with a 5-mm screen, and stored at room temperature in sealed bags until use.

\section{Chemical genomic analysis of hydrolysates}

Chemical genomic analysis of these hydrolysates was performed as described previously using a collection of $\sim 3500$ yeast deletion mutants $[19,36] .200 \mu \mathrm{L}$ cultures of the pooled collection of $S$. cerevisiae deletion mutants were grown anaerobically in the different versions of ACSH and ASGH, or yeast-rich medium (YPD, $20 \mathrm{~g} / \mathrm{L}$ peptone, $10 \mathrm{~g} / \mathrm{L}$ yeast extract, $20 \mathrm{~g} / \mathrm{L}$ glucose), diluted 1:1 with sterile water, in triplicate for $48 \mathrm{~h}$ at $30^{\circ} \mathrm{C}$. Genomic DNA was extracted from the cells and mutant-specific molecular barcodes were amplified using specially designed multiplex primers as described previously [19]. The barcodes were sequenced using an Illumina HiSeq 2500 in rapid run mode (Illumina, Inc., San Diego, CA). The barcode counts for each yeast deletion mutant in the hydrolysates were normalized against the synthetic hydrolysate control (SynH2.1) [16] in order to define sensitivity or resistance of individual strains (chemical genetic interaction score). The pattern of genetic interaction scores for all mutant strains represents the chemical genomic profile or "biological fingerprint" of a sample $[19,36]$. The clustergram of the chemical genomic profiles was created in Cluster 3.0 [37], and visualized in Treeview (v1.1.6r4) [38]. The $p$ value for the difference between 2012 ASGH and all other hydrolysates was calculated and Bonferroni corrected using the multtest package [39] in R-Studio ${ }^{\circledR}$. A Bonferroni-corrected hypergeometric distribution test was used to search for significant enrichment of GO terms among sets of highly resistant mutants (fitness $>2.5, n=224$ ) and highly susceptible mutants (fitness $<-2.5, n=409$ ) [40] using LAGO [41]. For the highly resistant and susceptible mutants for only 2012 ASGH or the four feedstocks but 
not 2012 ASGH, the GO terms were evaluated using only those terms that had statistically different fitness between the two groups $(p<0.001)$. Gene set enrichment analysis (GSEA) [42] was used to compare the enrichment of the KEGG pathways for S. cerevisiae between the 2012 ASGH and the four other feedstocks for genes that conferred statistically different fitness $(p<0.001)$.

\section{Untreated biomass composition analysis}

The composition of the untreated biomass was analyzed based on the NREL standard procedures for biomass composition analysis [43-47], with the following deviations. Samples for composition analysis were milled through a 2-mm screen using a Foss Cyclotec ${ }^{\mathrm{TM}}$ mill (Eden Prairie, $\mathrm{MN}$ ) and not sieved prior to analysis. The protein content was estimated by multiplying the nitrogen content as determined by a Skalar Primacs SN Total Nitrogen Analyzer (Breda, The Netherlands) by a conversion factor (6.25), which assumes that $16 \%$ of the protein is nitrogen. Although the preferred method is to calculate the protein content based on the amino acid profile of the biomass [48], this method is complex and so we chose to use an estimation. Water-soluble oligomeric sugars were determined by hydrolyzing the water extractives using sulfuric acid [49]. The hydrolyzed water extracts were then neutralized using calcium carbonate and both the hydrolyzed and non-hydrolyzed water extractives were run through an Aminex HPX-87P column (Bio-Rad, Hercules, CA) with attached guard columns [47] and analyzed for their sucrose, fructose, glucose, xylose, arabinose, galactose, and mannose concentrations based on calibration standards.

\section{Hydrolysate amino acid composition}

Prior to amino acid quantification, $50 \mu \mathrm{L}$ aliquots of samples were spiked with stable isotope labeled internal standards for the 20 common proteinogenic amino acids (Sigma-Aldrich Cell Free Amino Acid Mixture $-{ }^{13} \mathrm{C},{ }^{15} \mathrm{~N}$; $\mathrm{P} / \mathrm{N}$ 767964-1EA) and processed by solid-phase extraction (Phenomenex Strata-X-C cartridges; P/N 8B-S029$\mathrm{HCH})$ to remove matrix interferents. SPE-processed samples underwent vacuum centrifugation before resuspension in $1 \mathrm{~mL}$ of Mobile Phase A. Samples were then analyzed via LC-MS/MS, based on the protocol from $\mathrm{Gu}$ et al. [48], with the following modifications: mobile phase A was $10 \mathrm{mM}$ instead of $1 \mathrm{mM}$ (to reduce column equilibration time) and an LC gradient of $0.00-1.75 \min (98 \%$ A); $1.76-8.00 \mathrm{~min}$ (linear ramp to $45 \% \mathrm{~A}$ ); $8.01-9.00 \mathrm{~min}$ (10\% A); and 9.01-13.00 min (98\% A). Response factors were calculated based on the peak area of the selected multiple reaction monitoring (MRM) chromatograms for each compound relative to the area of the MRM peak for each amino acid's stable isotope labeled internal standard.

\section{Statistical analysis of hydrolysate composition}

Statistical analysis of the hydrolysate composition was conducted in R-Studio ${ }^{\circledR}$, version 0.98.1102 (Boston, MA). A linear model of each chemical component was developed based on the feedstock (corn stover or switchgrass), harvest year, and their interaction, with variety nested within feedstock. The model was evaluated using Tukey's HSD test based on 95\% confidence intervals (Agricolae package, version 1.2-1 [49]). When a reported value was below the limit of quantitation (LOQ), the value was recalculated as $\mathrm{LOQ} / \sqrt{2}$ [50]. These recalculated values were used to determine the mean, standard deviation, and statistical differences. The principal component analysis was conducted in R-Studio ${ }^{\circledR}$ and plots were generated using the ggbiplot package.

\section{Quantification of imidazoles and pyrazines in AFEX-treated Biomass}

AFEX-pretreated biomass was milled through a $2.0-\mathrm{mm}$ screen using a Foss Cyclotec ${ }^{\mathrm{TM}}$ mill (Eden Prairie, MN). The milled biomass was extracted with acetone using an Accelerated Solvent Extractor (Dionex ${ }^{\mathrm{TM}}$ ASE 200, Thermo Scientific) and the following conditions: $5 \mathrm{~min}$ heat, 5 min static, $150 \%$ flush volume, $120 \mathrm{~s}$ purge, two cycles, $1500 \mathrm{psi}$, and $70{ }^{\circ} \mathrm{C}$. Standards for the analyzed compounds were prepared in pure acetone in concentrations ranging from 0.00128 to $20 \mathrm{mg} / \mathrm{L}$. Internal standards of 4-methylimidazole- $\mathrm{d}_{6}$ (imidazole authentic standard) and 2-methylpyrazine- $\mathrm{d}_{6}$ (pyrazine authentic standard) were obtained from $\mathrm{C} / \mathrm{D} / \mathrm{N}$ Isotopes (PointeClaire, Quebec, Canada) and added to each sample, standard, and blank at a final concentration of $6 \mathrm{mg} / \mathrm{L}$. Samples were directly analyzed via GC-MS, without derivatization, based on the protocol from Chundawat et al. [23], with the following modifications to the GC temperature program: $40{ }^{\circ} \mathrm{C}(2 \mathrm{~min})$, from $5{ }^{\circ} \mathrm{C} / \mathrm{min}$ to $150{ }^{\circ} \mathrm{C}$ ( 1 min hold), $8{ }^{\circ} \mathrm{C} / \mathrm{min}$ to $200{ }^{\circ} \mathrm{C}$ ( 2 min hold), $20{ }^{\circ} \mathrm{C} / \mathrm{min}$ to $260{ }^{\circ} \mathrm{C}$ ( $3 \mathrm{~min}$ hold). Response factors were calculated based on the peak area of the selected ion chromatogram (molecular ion; $\mathrm{M}^{+}$) of each compound relative to the area of the internal standard peak.

\section{Determination of pyrazines and imidazoles in switchgrass hydrolysates by RP-HPLC-HR/AM-MS}

For each year of ASGH, $1 \mathrm{~mL}$ of hydrolysate was extracted with $0.5 \mathrm{~mL}$ ethyl acetate by vortex mixing for approximately $30 \mathrm{~s}$, then centrifuging at $16 \times g$ for $5 \mathrm{~min}$ to separate the layers. The organic (top) phase was collected and the procedure was repeated with another $0.5 \mathrm{~mL}$ ethyl acetate and the second organic extract combined with the first. $0.5-\mathrm{g}$ anhydrous sodium sulfate was added to the ethyl acetate extract, capped, and allowed to stand overnight before an aliquot was taken 
for analysis by GC-MS. Sample components were separated by an Agilent 7890A gas chromatograph equipped with an HP-5 MS column, $30 \mathrm{~m} \times 0.25 \mathrm{~mm}$ ID, initially at $40{ }^{\circ} \mathrm{C}$ for $2 \mathrm{~min}$ and then heated to $320{ }^{\circ} \mathrm{C}$ at $10{ }^{\circ} \mathrm{C} /$ min. Mass spectra were recorded with the interfaced Agilent $5975 \mathrm{MSD}$ from $\mathrm{m} / \mathrm{z} 40$ to 750 with an ionization energy of $70 \mathrm{eV}$. The GC inlet was set to $265^{\circ} \mathrm{C}$ and MS transfer line temperature was $250^{\circ} \mathrm{C}$. The inlet was operated in spilt mode with a split ratio of 10:1, and helium carrier gas flow rate through the column was held at $1 \mathrm{~mL} / \mathrm{min}$. Mass Hunter GC/MS acquisition software (Agilent) version B.07.00.1413 was used to control the instrument and collect the data. Identities of 2-methylpyrazine, 2,6-dimethylpyrazine, 2,3-dimethylpyrazine (the smaller peak immediately following the 2,6 isomer), (5-methylpyrazin-2-yl) methanol, and (6-methylpyrazin2-yl) methanol were confirmed by co-chromatography with authentic reference standards. Known amounts of authentic reference standards were individually added to aliquots of a composite mixture of the ethyl acetate extracts of all three batches of 2012 ASGH. The resulting chromatograms were compared to the chromatogram of the composite mixture without added standards. Singlepoint calibration gave a value of $300 \mu \mathrm{M} 2$-methylpyrazine in the extract. Further experiments suggested the actual value was higher due to incomplete extraction.

\section{Pyrazine and imidazole spike-in experiment}

To determine if the detected pyrazines and imidazoles contributed toward the inhibition of yeast in the 2012 ASGH, we grew yeast in 2010 ASGH supplemented with similar levels of pyrazines and imidazoles found in the 2012 ASGH. $10 \mu \mathrm{L}$ of exponentially growing Y128 S. cerevisiae [17] at a cell density of $\mathrm{OD}_{600}=1.0$ was inoculated in 96-well microtiter plates containing $190 \mu \mathrm{L}$. We grew triplicate, $200 \mu \mathrm{L}$ cultures of S. cerevisiae Y128 aerobically in each of the following hydrolysates: 2012 ASGH and 2010 ASGH supplemented with $0 \times, 1 \times, 10 \times, 25 \times$, $37.5 \times$, or $50 \times$ concentrations of the following pyrazines and imidazoles from 2012 ASGH dissolved in $\mathrm{ddH}_{2} \mathrm{O}$ : $1 \mu \mathrm{M}$ 1-methylimidazole, $140 \mu \mathrm{M}$ 2-methylimidazole, $360 \mu \mathrm{M}$ 4-methylimidazole, $6 \mu \mathrm{M}$ 2,4-dimethylimidazole, $430 \mu \mathrm{M}$ 2-methylpyrazine, $9 \mu \mathrm{M}$ 2,5-dimethylpyrazine, and $38 \mu \mathrm{M}$ 2,6-dimethylpyrazine (Sigma, USA). Cultures were incubated at $30{ }^{\circ} \mathrm{C}$ for $72 \mathrm{~h}$ and read every $11.3 \mathrm{~min}$ using a TECAN M1000 multimode plate reader housed within in an anaerobic chamber (Coy) maintained with $10 \% \mathrm{H}_{2}, 10 \% \mathrm{CO}_{2}$, and $80 \% \mathrm{~N}_{2}$ gases.

\section{$\mathrm{IC}_{50}$ of imidazoles and pyrazines}

To determine the half maximal inhibitory concentration $\left(\mathrm{IC}_{50}\right)$ of each pyrazine and imidazole, we created a 12-point dose curve of each compound. We grew
$200 \mu \mathrm{L}$ cultures of S. cerevisiae Y128 in synthetic hydrolysate (SynH2.1) [16] supplemented with a range of $0-10 \mathrm{mg} / \mathrm{mL}(0,0.5,1,2,3$, 4, etc.) of each of the following compounds separately: 2-methylimidazole, 4(5)-methylimidazole, 2,4-dimethylimidazole, 2-methylpyrazine, 2,3-dimethylpyrazine, 2,5-dimethylpyrazine, 2,6-dimethylpyrazine, 2,3,5-trimethylpyrazine, and (5-methylpyrazin-2-yl) methanol. We incubated these cultures for $48 \mathrm{~h}$ with $\mathrm{OD}_{595}$ readings taken every 15 min using a TECAN M500 (TECAN, USA). Biological replicates were conducted in triplicate. $\mathrm{IC}_{50}$ values were estimated using SigmaPlot 12.0 (Systat Software, San Jose, CA) and converted to molar concentrations for ease of comparison.

\section{Additional files}

Additional file 1. Chemical genomics dataset.

Additional file 2. Maps of significant gene ontology terms for chemical genomics data. Untreated biomass composition. Detailed hydrolysate composition.

\section{Abbreviations}

ACSH: AFEX-treated corn stover hydrolysate; ASGH: AFEX-treated switchgrass hydrolysate; AFEX: ammonia fiber expansion pretreatment; CS: corn stover; SG: switchgrass.

\section{Authors' contributions}

RGO designed the project, performed composition analysis and prep work for pyrazine and imidazole quantification, analyzed data, ran statistical analyses, analyzed chemical genomics data, and wrote the manuscript with input from all authors. LGO, DE, and GRS designed the project, coordinated collection and processing of biomass, analyzed data, and edited the manuscript. YZ designed the project, led hydrolysate production and fermentation experiments, analyzed data, and edited the manuscript. JS, DX, and EP generated hydrolysate, conducted fermentation experiments, analyzed data, and edited the manuscript. SAS, AH, ADJ and JJC designed and performed mass spectrometric analysis of biomass extracts and hydrolysates, analyzed data, and edited the manuscript. JSP designed the project, conducted chemical genomics experiments, analyzed data, and edited the manuscript. TKS, SB, and QD conducted chemical genomic experiments, individual compound toxicity tests, and spike-in experiments, analyzed data, and edited the manuscript. DMB and DC designed the project, analyzed data, and edited the manuscript. All authors read and approved the final manuscript.

\section{Author details}

${ }^{1}$ DOE Great Lakes Bioenergy Research Center, Michigan State University, East Lansing, MI, USA. ${ }^{2}$ Department of Chemical Engineering, Michigan State University, East Lansing, MI, USA. ${ }^{3}$ Department of Chemical Engineering, Michigan Technological University, Houghton, MI, USA. ${ }^{4}$ Department of Chemistry, University of Wisconsin-Madison, Madison, WI, USA. ${ }^{5}$ DOE Great Lakes Bioenergy Research Center, University of Wisconsin-Madison, Madison, WI, USA. ${ }^{6}$ RTSF Mass Spectrometry \& Metabolomics Core, Michigan State University, East Lansing, MI, USA. ${ }^{7}$ Department of Biochemistry \& Molecular Biology, Michigan State University, East Lansing, MI, USA. ${ }^{8}$ Department of Chemistry, Michigan State University, East Lansing, MI, USA. ${ }^{9}$ Department of Biomolecular Chemistry, University of Wisconsin-Madison, Madison, WI, USA. ${ }^{10}$ Genome Center of Wisconsin, University of Wisconsin-Madison, Madison, WI, USA. ${ }^{11}$ Department of Agronomy, University of Wisconsin-Madison, Madison, WI, USA.

\section{Acknowledgements}

We thank K. Keegstra, B. Landick, R. Jackson, J. Ralph, and B. Dale for feedback during preparation of the manuscript. We also thank Novozymes for providing 
the enzymes used during enzymatic hydrolysis; J. Sustachek, A. Miller, Z. Andersen, B. Faust, and J. Tesmer for collection and processing of biomass; $C$. Donald Jr. for AFEX pretreatment; M. Kreuger, M. Shabani, and C. Gunawan for biomass composition analysis; M. Kreuger for prep work for imidazole/pyrazine quantification; M. McGee for HPLC analysis of fermentation products; and the MSU Mass Spectrometry and Metabolomics Core for mass spectrometric analysis of biomass extracts and hydrolysates.

\section{Competing interests}

The authors declare that they have no competing interests.

\section{Availability of data and materials}

Correspondence and reasonable requests for data or materials should be addressed to R.G.O. (rgong1@mtu.edu).

\section{Funding}

This work was funded by the DOE Great Lakes Bioenergy Research Center (DOE BER Office of Science DE-FC02-07ER64494). Additional funding for L.G.O. is under DOE OBP Office of Energy Efficiency and Renewable Energy (DE-AC05-76RL01830). AFEX is a trademark of MBI, International (Lansing, MI).

Received: 18 August 2016 Accepted: 25 October 2016 Published online: 08 November 2016

\section{References}

1. Wang M, Han J, Dunn JB, Cai H, Elgowainy A. Well-to-wheels energy use and greenhouse gas emissions of ethanol from corn, sugarcane and celIulosic biomass for US use. Environ Res Lett. 2012;7(4):045905.

2. Perlack RD, Stokes BJ. US billion-ton update: biomass supply for a bioenergy and bioproducts industry. Oak Ridge: Oak Ridge National Laboratory; 2011. Report No.: ORNL/TM-2011/224.

3. Miguez FE, Maughan M, Bollero GA, Long SP. Modeling spatial and dynamic variation in growth, yield, and yield stability of the bioenergy crops Miscanthus $\times$ giganteus and Panicum virgatum across the conterminous United States. GCB Bioenergy. 2012:4(5):509-20.

4. Barney JN, Mann JJ, Kyser GB, Blumwald E, Van Deynze A, DiTomaso JM. Tolerance of switchgrass to extreme soil moisture stress: ecological implications. Plant Sci. 2009;177(6):724-32.

5. Chaves MM, Maroco JP, Pereira JS. Understanding plant responses to drought_-from genes to the whole plant. Funct Plant Biol. 2003;30:239-64

6. Ings J, Mur LAJ, Robson PRH, Bosch M. Physiological and growth responses to water deficit in the bioenergy crop Miscanthus $\times$ giganteus. Front Plant Sci. 2013;4:468

7. Emerson R, Hoover A, Ray A, Lacey J, Cortez M, Payne C, et al. Drought effects on composition and yield for corn stover, mixed grasses, and Miscanthus as bioenergy feedstocks. Biofuels. 2014:5(3):275-91.

8. Nichols VA, Miguez FE, Jarchow ME, Liebman MZ, Dien BS. Comparison of cellulosic ethanol yields from midwestern maize and reconstructed tallgrass prairie systems managed for bioenergy. Bioenergy Res. 2014:7(4):1550-60.

9. van der Weijde T, Huxley LM, Hawkins S, Sembiring EH, Farrar K, Dolstra O, et al. Impact of drought stress on growth and quality of miscanthus for biofuel production. GCB Bioenergy. 2016. doi:10.1111/gcbb.12382.

10. James LA, Swinton SM, Thelen KD. Profitability analysis of cellulosic energy crops compared to corn. Agron J. 2010;102(2):675-87.

11. Schmer MR, Vogel KP, Mitchell RB, Perrin RK. Net energy of cellulosic ethanol from switchgrass. Proc Natl Acad Sci USA. 2008;105(2):464-9.

12. Werling BP, Dickson TL, Isaacs R, Gaines H, Gratton C, Gross KL, et al. Perennial grasslands enhance biodiversity and multiple ecosystem services in bioenergy landscapes. Proc Natl Acad Sci USA. 2014;111(4):1652-7.

13. Oates LG, Duncan DS, Gelfand I, Millar N, Robertson GP, Jackson RD. Nitrous oxide emissions during establishment of eight alternative cellulosic bioenergy cropping systems in the North Central United States. GCB Bioenergy. 2016;8(3):539-49.

14. Stewart CE, Follett RF, Pruessner EG, Varvel GE, Vogel KP, Mitchell RB. Nitrogen and harvest effects on soil properties under rainfed switchgrass and no-till corn over 9 years: implications for soil quality. GCB Bioenergy. 2015:7(2):288-301.
15. Le PVV, Kumar P, Drewry DT. Implications for the hydrologic cycle under climate change due to the expansion of bioenergy crops in the Midwestern United States. Proc Natl Acad Sci USA. 2011;108(37):15085-90.

16. Serate J, Xie D, Pohlmann E, Donald C, Shabani M, Hinchman L, et al. Controlling microbial contamination during hydrolysis of AFEX-pretreated corn stover and switchgrass: effects on hydrolysate composition, microbial response and fermentation. Biotechnol Biofuels. 2015:8(1):1-17.

17. Parreiras LS, Breuer RJ, Avanasi Narasimhan R, Higbee AJ, La Reau A, Tremaine $\mathrm{M}$, et al. Engineering and two-stage evolution of a lignocellulosic hydrolysate-tolerant Saccharomyces cerevisiae strain for anaerobic fermentation of xylose from AFEX pretreated corn stover. PLOS ONE. 2014;9(9):e107499.

18. Zhang M, Chou Y-C, Howe W, Eddy C, Evans K, Mohagheghi A, inventors; USPTO, assignee. Zymomonas pentose-sugar fermenting strains and uses thereof. United States patent US7223575 B2. 29 May 2007.

19. Piotrowski JS, Simpkins SW, Li SC, Deshpande R, Mcllwain SJ, Ong IM, et al. Chemical genomic profiling via barcode sequencing to predict compound mode of action. In: Hempel JE, Williams CH, Hong CC, editors. Chemical biology, methods in molecular biology. New York: Springer; 2015. p. 299-318.

20. Redding K, Holcomb C, Fuller RS. Immunolocalization of Kex2 protease identifies a putative late Golgi compartment in the yeast Saccharomyces cerevisiae. J Cell Biol. 1991;113(3):527-38.

21. Bonifacino JS, Rojas R. Retrograde transport from endosomes to the trans-Golgi network. Nat Rev Mol Cell Biol. 2006;7(8):568-79.

22. Meyer E, Aspinwall MJ, Lowry DB, Palacio-Mejía JD, Logan TL, Fay PA, et al. Integrating transcriptional, metabolomic, and physiological responses to drought stress and recovery in switchgrass (Panicum virgatum L.). BMC Genom. 2014;15(1):1-15.

23. Chundawat SPS, Vismeh R, Sharma LN, Humpula JF, da Costa Sousa L, Chambliss CK, et al. Multifaceted characterization of cell wall decomposition products formed during ammonia fiber expansion (AFEX) and dilute acid based pretreatments. Bioresour Technol. 2010;101(21):8429-38.

24. Klinger KM, Liebner F, Fritz I, Potthast A, Rosenau T. Formation and ecotoxicity of $\mathrm{N}$-heterocyclic compounds on ammoxidation of mono- and polysaccharides. J Agric Food Chem. 2013;61(38):9004-14.

25. Georgopapadakou NH, Walsh TJ. Antifungal agents: chemotherapeutic targets and immunologic strategies. Antimicrob Agents Chemother. 1996:40(2):279-91.

26. Obata T, Witt S, Lisec J, Palacios-Rojas N, Florez-Sarasa I, Yousfi S, et al. Metabolite profiles of maize leaves in drought, heat, and combined stress field trials reveal the relationship between metabolism and grain yield. Plant Physiol. 2015;169(4):2665-83.

27. Lau MW, Dale BE. Cellulosic ethanol production from AFEX-treated corn stover using Saccharomyces cerevisiae 424A(LNH-ST). Proc Natl Acad Sci USA. 2009;106(5):1368-73.

28. Bower S, Wickramasinghe R, Nagle NJ, Schell DJ. Modeling sucrose hydrolysis in dilute sulfuric acid solutions at pretreatment conditions for lignocellulosic biomass. Bioresour Technol. 2008;99(15):7354-62.

29. Heer D, Sauer U. Identification of furfural as a key toxin in lignocellulosic hydrolysates and evolution of a tolerant yeast strain. Microb Biotechnol. 2008;1(6):497-506.

30. Almeida JRM, Bertilsson M, Gorwa-Grauslund MF, Gorsich S, Lidén G. Metabolic effects of furaldehydes and impacts on biotechnological processes. Appl Microbiol Biotechnol. 2009;82(4):625-38.

31. Gelfand I, Sahajpal R, Zhang XS, Izaurralde RC, Gross KL, Robertson GP. Sustainable bioenergy production from marginal lands in the US Midwest. Nature. 2013;493(7433):514-7.

32. Quinn LD, Straker KC, Guo J, Kim S, Thapa S, Kling G, et al. Stress-tolerant feedstocks for sustainable bioenergy production on marginal land. Bioenergy Res. 2015;8(3):1081-100.

33. Trenberth KE, Dai AG, van der Schrier $G$, Jones PD, Barichivich J, Briffa $\mathrm{KR}$, et al. Global warming and changes in drought. Nature Clim Change. 2014;4(1):17-22.

34. NWS. National weather service: Wisconsin 30 year average temperature 2013. http://www.crh.noaa.gov/images/mkx/climate/avg_30_year_temp. png. Accessed 2 Apr 2014.

35. NWS. National weather service: Wisconsin 30 year average precipitation. 2013. http://www.crh.noaa.gov/images/mkx/climate/avg_30_year_precip.png. Accessed 2 Apr 2014 
36. Piotrowski JS, Okada H, Lu FC, Li SC, Hinchman L, Ranjan A, et al. Plantderived antifungal agent poacic acid targets $\beta-1,3-g l u c a n$. Proc Natl Acad Sci USA. 2015;112(12):E1490-7.

37. de Hoon MJL, Imoto S, Nolan J, Miyano S. Open source clustering software. Bioinformatics. 2004;20(9):1453-4.

38. Page RDM. Tree view: an application to display phylogenetic trees on personal computers. Comput Appl Biosci. 1996;12(4):357-8.

39. Pollard KS, Dudoit S, van der Laan MJ. Multiple testing procedures: the multtest package and applications to genomics. In: Gentleman R, Carey VJ, Huber W, Irizarry RA, Dudoit S, editors. Bioinformatics and computational biology solutions using R and bioconductor. New York: Springer; 2005. p. 249-71.

40. Boyle El, Weng S, Gollub J, Jin H, Botstein D, Cherry JM, et al. GO::termfinder-open source software for accessing gene ontology information and finding significantly enriched gene ontology terms associated with a list of genes. Bioinformatics. 2004;20(18):3710-5.

41. LAGO: A logically accelerated GO term finder. http://go.princeton.edu/ cgi-bin/LAGO. Accessed 20 July 2016.

42. Subramanian A, Tamayo P, Mootha VK, Mukherjee S, Ebert BL, Gillette MA, et al. Gene set enrichment analysis: a knowledge-based approach for interpreting genome-wide expression profiles. Proc Natl Acad Sci USA. 2005:102(43):15545-50

43. Sluiter A, Hames B, Ruiz R, Scarlata C, Sluiter J, Templeton D. Determination of ash in biomass. Golden: National Renewable Energy Laboratory: 2008. Report No.: NREL/TP-510-42622.
44. Sluiter A, Hames B, Ruiz R, Scarlata C, Sluiter J, Templeton D et al. Determination of structural carbohydrates and lignin in biomass. Golden: National Renewable Energy Laboratory; 2012. Report No.: NREL/ TP-510-42618.

45. Sluiter A, Ruiz R, Scarlata C, Sluiter J, Templeton D. Determination of extractives in biomass. Golden: National Renewable Energy Laboratory; 2008. Report No.: NREL/TP-510-42619.

46. Hames B, Scarlata C, Sluiter A. Determination of protein content in biomass. Golden: National Renewable Energy Laboratory; 2008. Report No.: NREL/TP-510-42625.

47. Sluiter A, Hames B, Ruiz R, Scarlata C, Sluiter J, Templeton D. Determination of sugars, byproducts, and degradation products in liquid fraction process samples. Golden: National Renewable Energy Laboratory; 2008. Report No.: NREL/TP-510-42623.

48. Gu LP, Jones AD, Last RL. LC-MS/MS assay for protein amino acids and metabolically related compounds for large-scale screening of metabolic phenotypes. Anal Chem. 2007;79(21):8067-75.

49. De Mendiburu F. Una herramienta de analisis estadistico para la investigacion agricola. Universidad Nacional de Ingenieria (UNI-PERU); 2009.

50. Croghan C, Egeghy P. Methods of dealing with values below the limit of detection using SAS. St. Petersburg: Southern SAS User Group; 2003.

51. Garlock RJ, Bals B, Jasrotia P, Balan V, Dale BE. Influence of variable species composition on the saccharification of $A F E X^{\mathrm{TM}}$ pretreated biomass from unmanaged fields in comparison to corn stover. Biomass Bioenergy. 2012;37:49-59.

\section{Submit your next manuscript to BioMed Central and we will help you at every step:}

- We accept pre-submission inquiries

- Our selector tool helps you to find the most relevant journal

- We provide round the clock customer support

- Convenient online submission

- Thorough peer review

- Inclusion in PubMed and all major indexing services

- Maximum visibility for your research

Submit your manuscript at www.biomedcentral.com/submit 